\title{
Information Sheet \\ Does taking up a new activity benefit our thinking skills?
}

You are being invited to take part in a research study at Heriot-Watt University exploring how taking up a new activity might benefit our thinking skills.

Before you decide whether or not to take part, it is important for you to understand why the research is being done and what it will involve. Please take time to read the following information carefully. Talk to others about the study if you wish. Contact us if there is anything that is not clear or if you would like more information. Take time to decide whether or not you wish to take part.

\section{What is the purpose of the study?}

Research suggests that as we grow older, we are more likely to experience general changes in our thinking and memory skills. Some individuals experience noticeable mental decline across their 60s and beyond, while others maintain their thinking skills into old age. This variation suggests that a number of factors influence how well people maintain their thinking skills as they get older. Keeping engaged in intellectual, social or physical activities have all been proposed as potentially beneficial. The purpose of the study is to better understand what kind of activities can reduce or delay changes in thinking skills with age.

\section{Do I have to take part?}

No, it is up to you to decide whether or not to take part. If you do decide to take part you will be given this information sheet to keep and be asked to sign a consent form. If you decide to take part you are still free to withdraw at any time and without giving a reason. Deciding not to take part or withdrawing from the study will not affect the healthcare that you receive, or your legal rights.

\section{What will happen if I take part?}

You will meet with a researcher at Heriot-Watt University on two occasions. During your first visit, you will complete some assessments of memory, attention and other cognitive functions. You will also complete some questionnaires related to your background, current health and well-being, and some physical tests that measure blood pressure, grip strength and lung capacity. A saliva sample will also be collected. The saliva sample will be tested for different genes later on. The saliva sample stored for gene testing will be kept completely anonymous as these tests are of no importance for your health as an individual.

The researcher will explain each assessment, and you will be able to ask any questions as you go along. The testing session will last about 2.5 hours, and there will be time for breaks. We can reimburse travel expenses to get to the university.

After completing these assessments, you will be randomly allocated into one of six activities that could be any of the following: computer classes, participation in social clubs, bingo, exercise or sport classes, gardening, dance or drama groups, musical instrument or language classes, and woodcraft. The group you are put into will not be based on your test performance. Participants need to be randomly assigned to each 
group to ensure that any changes we observe as a result of taking up a new activity are not because of initial differences between participants.

You will be provided with all the necessary equipment and any class fees will be covered. You will be expected to attend your allocated group for the duration of the course. The activity duration will be around 2 hours per week and will run for between 10-12 weeks.

After you complete your new activity course, you will return for another testing session at Heriot-Watt University. You will be asked to repeat the cognitive and health measures taken at the first session, and your visit will again last about 2.5 hours. This will allow us to explore how participation in a new activity is associated with any changes in thinking skills or health measures over time. Again, your travel expenses can be reimbursed and you will also be given a gift voucher to thank you for taking part.

In summary, your involvement in the study would be as follows:

- Visit 1: Complete assessments of thinking skills and physical health, and questionnaires about lifestyle and wellbeing at Heriot-Watt University;

- New activity: Take up a new activity in the community (usually about 2 hours a week for 10-12 weeks, with class costs reimbursed);

- Visit 2: Return to Heriot-Watt to repeat the assessments of thinking skills and physical health, and questionnaires about lifestyle and wellbeing.

After completing this second assessment, you will be given the opportunity to complete a second new activity, or return to complete some further tests after about 3 months. You do not need to decide on that just now as you'll be given fuller details at the time.

\section{What are the possible benefits of taking part?}

You may or may not get a direct benefit from taking part in this study though all participants will attend a new activity free of charge. The outcomes of the study will, however, help us to better understand how taking up new activities might benefit thinking skills.

\section{What are the possible disadvantages and risks of taking part?}

It is not thought that there are many disadvantages. It is highly unlikely that participation in this study will cause you to become bored, tired or distressed; however, if this happens, you can stop at any time. If you become distressed for any reason, you may discuss this with any of the researchers listed below. You may also contact the Ethics Committee at Heriot-Watt University at sls.ethics@hw.ac.uk.

\section{Who can I contact if I am concerned about my health?}

The researchers involved in this study are not medical practitioners. They can discuss your concerns at the end of the study, but it is suggested that you contact your GP for any health-related issues.

\section{What if there is a problem?}

If you have a concern about any aspect of this study please contact the Ethics Committee at Heriot-Watt University [sls.ethics@hw.ac.uk] who will do their best to answer your questions. 


\section{Reimbursement}

You will be reimbursed for your travel expenses, and refreshments will be provided during the assessment sessions. After you complete the study you will receive a gift voucher.

\section{What happens when the study is finished?}

At the end of the research, with your permission we will retain the information you provide (including the saliva sample) should further analysis be possible in the future. We will retain your contact details so we can update you on the findings of the study, if you wish. Your contact details will be stored separately from the other data collected.

\section{Will my taking part in the study be kept confidential?}

All information collected from you is confidential and there are strict laws which safeguard your privacy at every stage. We will not have access to any other information about you or your health, other than the details you provide us with during. Your identity will not be revealed to anyone outside the research team. With your consent we will inform your GP that you are taking part. If there are any concerns raised during the study (for example if your blood pressure reading is somewhat high), we may pass these details to your GP to follow-up with you with your permission.

Storage of data Storage of the data collected will adhere to the Heriot-Watt University regulations and kept on Heriot-Watt University premises safe from unauthorised access, accidental loss or destruction until the end of the study.

\section{What will happen to the results of the study?}

There will be no provision for individual feedback. The study will be written up as one or more journal articles, and included in conference presentations. You will not be identifiable in any published results. At the end of the study, we will prepare a summary of the overall results for all volunteers.

\section{Who is organising the research and why?}

This study is being organised The Ageing Lab at Heriot-Watt University to explore how activities might affect thinking skills as we age. The study is funded by Velux Stiftung.

\section{Who has reviewed the study?}

The study has been reviewed by the School of Social Sciences Ethics Committee at Heriot-Watt University, and the NHS South East Scotland Research Ethics Committee.

If you have any further questions about the study please contact the research team below. If you would like to discuss this study with someone independent of the study please contact the Ethics Committee at Heriot-Watt University [sls.ethics@hw.ac.uk].

\section{For information about any aspect of this study, please contact:}

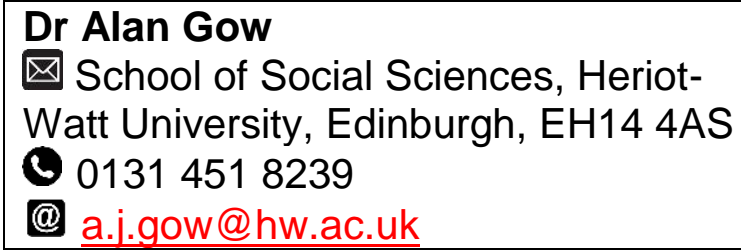

For more information on the study, you can visit the website: www.healthyageing.hw.ac.uk 